\title{
Marine research and management topics addressed by process-based ecosystem models
}

\author{
Solfrid Sætre Hjøllo ${ }^{1, *}$, Sonja M. van Leeuwen ${ }^{2}$, Marie Maar ${ }^{3}$ \\ ${ }^{1}$ Institute of Marine Research, 5817 Bergen, Norway \\ ${ }^{2}$ Department of Coastal Systems, NIOZ Royal Netherlands Institute for Sea Research, 1790 AB Den Burg (Texel), \\ The Netherlands \\ ${ }^{3}$ Department of Ecoscience, Aarhus University, 4000 Roskilde, Denmark
}

\begin{abstract}
The earth's oceans and ecosystems face climatic changes and multiple anthropogenic stressors. In the face of this, managers of the marine environment are increasingly adopting the ecosystem approach to underpin their decision making. Process-based ecosystem models (frequently referred to as dynamic models) synthesize existing observational and experimental knowledge into a numerical framework, but an obstacle to the incorporation of these models in management is the lack of credibility due to limited control of uncertainty in the results. The 13 papers in this Theme Section highlight how ecosystem models are, or can be, applied as management tools, and the various ways in which they quantify uncertainty and evaluate the skill. The papers span all levels of biological organization from individuals to populations and ecosystems, and cover a wide selection of anthropogenic pressures. Bearing in mind that the interpretation of observations is in fact also a model with representativeness error, we advocate a closer combination of observations and models to bring both methods forward. With the current challenges to the marine ecosystem and our uses of it, the more tools marine managers have in their 'toolbox', the better; dynamic modelling is one such very important tool, and its inclusion in ecosystem management should be continuously assessed.
\end{abstract}

KEY WORDS: Marine management $\cdot$ Ecosystem modelling $\cdot$ End-to-end models $\cdot$ Uncertainty

\section{INTRODUCTION}

Our marine environment is under pressure. Surface temperatures are increasing, and the ocean dynamics are changing (Masson-Delmotte et al. 2021), fishing and aquaculture are projected to increase (FAO 2020), while the global marine animal biomass is projected to decline (Lotze et al. 2019). The earth's oceans and seas face climatic changes and varying human pressures, and it is increasingly recognized that their combined impact may be different from the impacts of the separate parts. Marine

${ }^{*}$ Corresponding author: solfrid.hjollo@hi.no management is thus becoming more holistic, using the ecosystem approach (e.g. by using Integrated Ecosystem Assessments or IEAs) that considers all components, including social and economic interests. To implement the ecosystem approach, marine managers seek tools to understand and weigh trade-offs of their decisions (Pinnegar et al. 2021).

Dynamic ecosystem models are suitable for this purpose: they quantify processes that are difficult or impossible to measure, reveal ecosystem functions and complex food web interactions (e.g. trophic cascading effects) and evaluate responses of the local or

() The authors 2021. Open Access under Creative Commons by Attribution Licence. Use, distribution and reproduction are unrestricted. Authors and original publication must be credited. 
wider ecosystem components to bottom-up and top-down pressures from human activities and natural drivers (Peck et al. 2018, Skogen et al. 2021 in this Theme Section). For predictions about the future ocean, models are the only tool to study long-term ecosystem responses to marine stressors and indicate whether the combined stressor response is antagonistic, additive or synergistic.

This Theme Section highlights how ecosystem models can support management, but also the close interplay between models and observations. The papers span all levels of biological organization from individuals to populations and ecosystems, and cover a wide selection of anthropogenic pressures, such as fishery, climate change, ocean acidification and habitat destruction. A suite of different ecosystem models is applied for both coastal and open ocean situated study areas around the globe.

\section{QUANTIFYING UNCERTAINTY AND EVALUATING THE SKILL OF COMPLEX MODELS}

Why are ecosystem models not the preferred tool for marine managers? An obstacle to the incorporation of dynamic ecosystem models in management is the lack of credibility due to limited control of uncertainty (Payne et al. 2016, Steenbeek et al. 2021). Uncertainty is a fundamental component of managing complex systems and needs to be communicated to stakeholders. Even though uncertainty applies to both observations and modelled results, only the latter usually lead to management skepticisms because of uncertainty concerns (Skogen et al. 2021).

Several steps in the modelling process have embedded uncertainty, and they are explored in various ways in this Theme Section. Firstly, both forcing data and parameter settings introduce uncertainty. Physical forcing data are often not ensembles. The initial state of the ecosystem is seldom well known, and a high number of constants and processes needs to be parametrized using field-collected, experimental and/or real-world data and expert knowledge. To overcome the lack of knowledge, 'anchoring' (the use of parameters from related species with similar life traits, see Maps \& Record 2020) is common in ecosystem modelling. Sensitivity studies on the parameter settings typically focus on physiology and energetics of species (specific growth, survival, mortality, fecundity, larval stage duration and similar rates are examples from the studies in this Theme Section). However, when models also include human components, sensitivity studies of other types of model parameters are needed, as exemplified in Hansen et al. (2021 in this Theme Section) for a newly developed Calanus finmarchicus fishing vessel module. The importance of targeted observations for realistic model application is shown by Zhang et al. (2021 in this Theme Section), who provide new perspectives for understanding phytoplankton dynamics in the subarctic northeastern Pacific Ocean by incorporating high-resolution data from Biogeochemical-Argo floats in a water column ecosystem model with an Fe-cycle. They found that the phytoplankton biomass remains low during summer due to iron limitation and grazing pressure, and the model can be used to study the influence of ocean acidification on iron limitation in the future.

Secondly, uncertainty related to model structure can be explored by building ensembles of models and identifying where they converge on common predictions. An example of using different realizations of the same model to assess uncertainty is given by Hatzonikolakis et al. (2021 in this Theme Section), who use an ensemble of parameterization perturbations in a swordfish bioenergetics model to reveal high sensitivity to parameters related to the consumption-respiration balance. Van de Wolfshaar et al. (2021 in this Theme Section) evaluated the sensitivity of the North Sea fish community to 5 different prey fields in a 3D food web model. They found that differences in the spatial-temporal patterns and the size bins of the prey fields caused high variation in the fish biomass level, whereas the relative contribution of different fish groups was more robust. Also focusing on the North Sea ecosystem, Spence et al. (2021 in this Theme Section) applied the ensemble approach of Spence et al. (2018) to explore consequences of management actions; they integrated 5 different ecosystem model results and estimated changes in ecosystem state due to a range of fisheries management scenarios within a single probabilistic forecast.

Lastly, standardized uncertainty analysis and skill assessment are lacking in the literature, although some general validation guidelines have been published (see Olsen et al. 2016 and references therein). The complexity of some ecosystem models may limit the application of standardized uncertainty analysis such as Monte Carlo approaches, but in a common sole (Solea solea) model, Champagnat et al. (2021 in this Theme Section) estimated all parameters by assimilating an extensive data set by using Monte Carlo Markov Chain methods. Skill evaluation can be focused on biological parameters (e.g. reproductive potential, consumption and survival success 
of younger life stages of anchovy Engraulis mordax as in Politikos et al. 2021 in this Theme Section) or on management indicators (e.g. observed spawnerrecruit relationship used in the recent stock assessment of winter flounder Pseudopleuronectes americanus in Huebert et al. 2021 in this Theme Section). Due to the generally sparse marine data available, uncertainty analysis can also be hampered by the lack of high-quality, independent evaluation data truly representing the parameter or process of interest. Hjøllo et al. (2021 in this Theme Section) demonstrated how fully spatial (3D) ecosystem models can be used to mechanistically interpret observational data sets, exemplified for the sampling of zooplankton (Calanus finmarchicus) biomass in the Norwegian Sea. They found that 9 previously applied sampling patterns caused the observed zooplankton biomass to vary highly within the same month, while the more recent sampling strategy is more representative of a larger area and the inter-annual variability. Bearing in mind that the interpretation of observations is in fact also a model, formed by the individual observer, Skogen et al. (2021) discuss at a general level the representativeness errors of both observations and models, and conclude that combining models and data through refinement of model formulations and targeted data collection and analyses would bring us closer to uncover the secrets of the ecosystem.

\section{APPLICATION OF MODELS TO SUPPORT MANAGEMENT QUESTIONS}

Complex dynamic models have evolved over the last $30 \mathrm{yr}$ and can now be reliable representations of marine systems and their key species when they have gained credibility through a thorough uncertainty and skill assessment analysis. They are instrumental in ecosystem-based management due to the need for tools that can take a holistic approach including the quantification of scenario analyses (Piroddi et al. 2015, 2021). This Theme Section provides several examples of how model products can be applied as management tools, to inspire future applications.

Both Myksvoll et al. (2021 in this Theme Section) and Champagnat et al. (2021) demonstrate the benefit of including observations from many different sources in order to build a comprehensive context for a higher trophic level model in which possible management actions can be simulated. The sources include not only fish-based observations but also seabed properties, currents and chemical properties like nutrient and toxin concentrations. As such, single-species models are moving towards integrating the ecosystem approach without building a full endto-end ecosystem model. Both studies emphasize that their specific species model can also be used in end-to-end studies as part of the model continuum.

Myksvoll et al. (2021), Huebert et al. (2021), Politikos et al. (2021), Champagnat et al. (2021) and Pastor et al. (2021 in this Theme Section) all use individual-based models to help answer real-life management questions on early life stages of the commercial species saithe Pollachius virens, winter flounder Pseudopleuronectes americanus, anchovy Engraulis mordax, common sole Solea solea and blue mussel Mytilus edulis, respectively. Early life stages are critical to recruitment success and for adult stock biomass, and their response to the current oceanic stressors is not well known (Llopiz et al. 2014). Saithe eggs showed both earlier and accelerated hatching when exposed to higher temperatures (Myksvoll et al. 2021). Ocean acidification impacts on winter flounder are limited to reduced larval growth but exacerbate the abundance decline caused by climate change impacts on the species (Huebert et al. 2021). Improving water quality at existing nursery grounds of common sole can dramatically increase egg and larval survival (and future fecundity) and provides more benefits than increasing nursery habitat size (Champagnat et al. 2021). Warm years (related to strong El Niño events and thus negative El NiñoSouthern Oscillation phases) found lower survival and growth rate of anchovy eggs and larvae in the California Current System, resulting in decreased recruitment due to different adult behaviour prior to spawning (Politikos et al. 2021). Myksvoll et al. (2021) linked northward movement of saithe eggs and larvae to positive North Atlantic Oscillation (NAO) phases (increasing connectivity between the different spawning areas) and coastal nursery retention to negative NAO phases (reducing connectivity). As such, large scale regional variability can have a strong impact on local spawning success and recruitment, and subsequently stock biomass. This impact should be taken into account in stock management plans. On a more local scale, the dispersal of mussel larvae and the connectivity of natural mussel populations in a fjord system were found to be high despite hydrographical boundaries, which are important for the recruitment of mussels and the site-selection of mussel aquaculture (Pastor et al. 2021).

These studies also raise concerns about the current way stocks are managed, i.e. in separate manage- 
ment areas. Champagnat et al. (2021) show that although common sole in different parts of the Eastern English Channel have low connectivity, the restoration of a single suitable nursery habitat can increase the spawning biomass and stock biomass in the wider region if considered as one meta-population. Myksvoll et al. (2021) find a well-connected northeastern Atlantic saithe population that is split over 4 different management areas. At the same time, an isolated stock around Rockall (west of Scotland) is included in the North Sea management area. These types of mismatches, where either (1) a species displays high connectivity over a large area split into separate management units, or (2) an isolated species is included in a larger management area with multiple populations, increase the risk of overexploitation of a species. Dynamic models can help define better management areas to mitigate this risk.

A central application of dynamic ecosystem models for management is quantification of management scenarios. Hatzonikolakis et al. (2021) provide an estimation of swordfish (Xiphias gladius) egg production in the Mediterranean Sea and show that despite the population-wide spawning season of $\sim 90 \mathrm{~d}$, individual swordfish are reproductively active for only $\sim 15 \mathrm{~d}$. The results emphasize that environmental factors should be included in future stock projections, advocating the use of end-to-end models for that purpose. Single species life cycle models are critical components in end-to-end studies when providing specific commercial stock management advice. For swordfish, this tool is now available (Hatzonikolakis et al. 2021), with obvious management benefits. Hansen et al. (2021) show that fisheries of Calanus finmarchicus are sustainable in the Norwegian Sea. Simulating both current fishing vessels and optimal fishing vessels (with perfect knowledge of concentrated biomass locations), they show that in neither fishing scenario, vessels are able to catch the full current quota for the species. The model Hansen et al. (2021) applied is a 2-way coupled model, where plankton fields drive higher trophic levels, and fish biomass drives planktonic predation pressure. Spence et al. (2021) apply ensemble modelling to show that if maximum sustainable yield (MSY) quotas are adhered to, the North Sea fish community will recover its size-structure and species composition. More gain in biodiversity can be achieved by fishing below MSY, indicating a tradeoff between yield and biodiversity that can inform fisheries management.

For a full end-to-end modelling study, the motivations and options of the primary stakeholders and their dependents should be taken into account. Van Leeuwen et al. (2021 in this Theme Section) demonstrate this possibility by including both natural and social science modelling in one study. They applied an end-to-end model to evaluate future changes in a Chilean inner sea ecosystem that are due to climate change, ocean acidification and fisheries. Stakeholders from a local, small fisheries community were involved to identify key resources and concerns and helped to define the fisheries scenarios, while the model was used to determine the future impact range. Higher trophic level results indicate that some targeted pelagic resources will decline (while benthic ones may benefit), but that these effects might be mitigated by strong fisheries management efforts. The model results can help the local community in their efforts to plan a sustainable economic future. Stakeholder perceptions are an important element of interdisciplinary management tools and should be taken into account in modelling studies.

\section{SUMMARY}

Applications with coupling of hydrodynamic models to lower or higher trophic level dynamic models (Fig. 1) are now common in the literature. Likewise, the input from lower trophic level models (e.g. prey

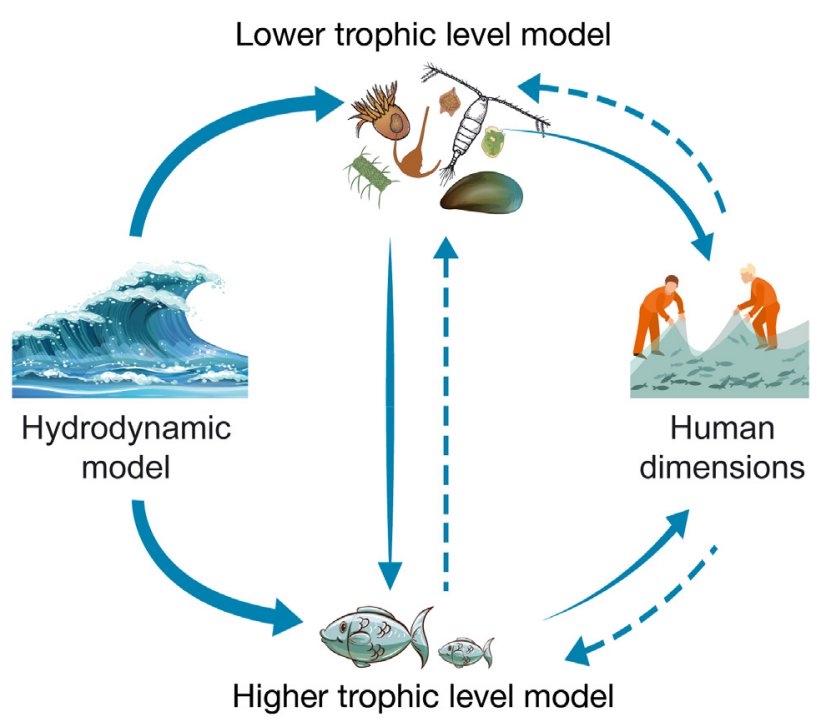

Fig. 1. Connections between hydrodynamic and trophic models with the human dimension. Solid arrows represent widely modelled feedback processes, while the dashed arrows are connections between models and drivers that are less often included in ecosystem models. Arrow thickness represents frequency of application. Image: ICES Working Group on Integrated, Physical-biological and Ecosystem Modelling 
fields) to higher trophic level models and their connection (e.g. stock assessment, productivity) to the human dimension have been applied in several studies. However, the coupling from higher to lower trophic level models (e.g. predation) is rarer. End-toend models including the full coupling of all trophic levels with 2-way interaction of the human dimension exist, although in lower numbers due to their high complexity. The examples included in this Theme Section all use dynamic coupled models, and most provide a clear message to management questions. It is therefore time to focus on the inclusion of dynamic modelling in the management toolbox, because we need all available tools in these challenging times to safeguard the marine ecosystem and our uses thereof. Using models and observations together in management will allow us to increase our understanding in a synergetic way, providing more benefit than by using just the separate parts (Skogen et al. 2021).

Acknowledgements. We acknowledge the invaluable work from the Guest Editors Aaron Adamack, Lisandro BenedettiCecchi, Alejandro Gallego, Myron Peck, Corinna Schrum, Ingrid van Putten, Brian Wells, and the Editorial staff at MEPS. We also thank all contributors to session $O$ of the ICES Annual Science Conference 2020/2021. The inspiring collaboration among the members of the ICES Working Group on Integrative, Physical-biological and Ecosystem Modelling (WGIPEM) has been crucial for the appearance of this Theme Section.

\section{LITERATURE CITED}

Champagnat J, Lecomte JB, Rivot E, Douchet L and others (2021) Multidisciplinary assessment of nearshore nursery habitat restoration for an exploited population of marine fish. Mar Ecol Prog Ser 680:97-109

FAO (Food and Agriculture Organization of the United Nations) (2020) The state of world fisheries and aquaculture 2020: sustainability in action. FAO, Rome

Hansen C, Skogen MD, Utne KR, Broms C, Strand E, Hjøllo SS (2021) Patterns, efficiency and ecosystem effects when fishing Calanus finmarchicus in the Norwegian Sea-using an individual-based model. Mar Ecol Prog Ser 680:15-32

Hatzonikolakis Y, Tsiaras K, Tserpes G, Somarakis S and others (2021) Investigating growth and reproduction of Mediterranean swordfish Xiphias gladius through a full life cycle bioenergetics model. Mar Ecol Prog Ser 680:51-77

Hjøllo SS, Hansen C, Skogen MD (2021) Assessing the importance of zooplankton sampling patterns with an ecosystem model. Mar Ecol Prog Ser 680:163-176

Huebert KB, Rose KA, Chambers RC (2021) Simulating fish population responses to elevated $\mathrm{CO}_{2}$ : a case study using winter flounder. Mar Ecol Prog Ser 680:137-161

Masson-Delmotte V, Zhai P, Pirani A, Connors SL and others (eds) (2021) Climate change 2021: the physical science basis: Working Group I contribution to the Sixth Assessment Report of the Intergovernmental Panel on Climate Change. Cambridge University Press, Cambridge. www. ipcc.ch/report/ar6/wg1

* Llopiz JK, Cowen RK, Hauff MJ, Ji R and others (2014) Early life history and fisheries oceanography: new questions in a changing world. Oceanography (Wash DC) 27:26-41

Lotze HK, Tittensor DP, Bryndum-Buchholz A, Eddy TD and others (2019) Global ensemble projections reveal trophic amplification of ocean biomass declines with climate change. Proc Natl Acad Sci USA 116:12907-12912

*Maps F, Record NR (2020) Marine ecosystems model development should be rooted in past experiences, not anchored in old habits. ICES J Mar Sci 77:46-57

*Myksvoll MS, Devine J, Quintela M, Geffen AJ and others (2021) Linking dispersal connectivity to population structure and management boundaries for saithe in the Northeast Atlantic. Mar Ecol Prog Ser 680:177-191

Olsen E, Fay G, Gaichas S, Gamble R, Lucey S, Link JS (2016) Ecosystem model skill assessment. Yes we can! PLOS ONE 11:e0146467

* Pastor A, Larsen J, Hansen FT, Simon A, Bierne N, Maar M (2021) Agent-based modeling and genetics reveal the Limfjorden, Denmark, as a well-connected system for mussel larvae. Mar Ecol Prog Ser 680:193-205

Payne MR, Barange M, Cheung WWL, MacKenzie BR and others (2016) Uncertainties in projecting climate-change impacts in marine ecosystems. ICES J Mar Sci 73: 1272-1282

Peck MA, Arvanitidis C, Butenschön M, Canu DM and others (2018) Projecting changes in the distribution and productivity of living marine resources: a critical review of the suite of modelling approaches used in the large European project VECTORS. Estuar Coast Shelf Sci 201: 40-55

พ Pinnegar JK, Hamon KG, Kreiss CM, Tabeau A and others (2021) Future socio-political scenarios for aquatic RESources in Europe: A common framework based on shared-socioeconomic-Pathways (SSPs). Front Mar Sci 7: 568219

* Piroddi C, Teixeira H, Lynam CP, Smith C and others (2015) Using ecological models to assess ecosystem status in support of the European Marine Strategy Framework Directive. Ecol Indic 58:175-191

*Piroddi C, Akoglu E, Andonegi E, Bentley JW and others (2021) Effects of nutrient management scenarios on marine food webs: a pan-European assessment in support of the Marine Strategy Framework Directive. Front Mar Sci 8:596797

*Politikos DV, Rose KA, Curchitser EN, Checkley Jr DM, Rykaczewski RR, Fiechter J (2021) Climate variation and anchovy recruitment in the California Current: a causeand-effect analysis of an end-to-end model simulation. Mar Ecol Prog Ser 680:111-136

* Skogen MD, Ji R, Akimova A, Daewel U and others (2021) Disclosing the truth: Are models better than observations? Mar Ecol Prog Ser 680:7-13

Spence MA, Blanchard JL, Rossberg AG, Heath MR and others (2018) A general framework for combining ecosystem models. Fish Fish 19:1031-1042

Spence MA, Griffiths CA, Waggitt JJ, Bannister HJ, Thorpe RB, Rossberg AG, Lynam CP (2021) Sustainable fishing can lead to improvements in marine ecosystem status: an ensemble-model forecast of the North Sea ecosystem. Mar Ecol Prog Ser 680:207-221 
Steenbeek J, Buszowski J, Chagaris D, Christensen V and others (2021) Making spatial-temporal marine ecosystem modelling better - a perspective. Environ Model Softw 145:105209

van de Wolfshaar KE, Daewel U, Hjøllo SS, Troost TA and others (2021) Sensitivity of the fish community to different prey fields and importance of spatial-seasonal patterns. Mar Ecol Prog Ser 680:79-95
* ${ }^{*}$ van Leeuwen SM, Salgado H, Bailey JL, Beecham J, Iriarte JL, García-García L, Thorpe R (2021) Climate change, marine resources and a small Chilean community: making the connections. Mar Ecol Prog Ser 680: 223-246

* Zhang HR, Wang Y, Xiu P, Chai F (2021) Modeling the seasonal variability of phytoplankton in the subarctic northeast Pacific Ocean. Mar Ecol Prog Ser 680:33-50 